\title{
Entrevista major Eduardo Gomes Pinheiro
}

\author{
Por Norman Arruda Filho e Kathya Balan
}

\section{Apresentação}

O Brasil já enfrentou eventos extremos ao longo de sua história, mas o ano de 2011 foi um marco recente para que o estado do Paraná passasse a atuar, de forma mais consistente, com o apoio técnico do Banco Mundial, na Gestão de Riscos de Desastres (GRD).

Naquele ano, chuvas torrenciais impactaram quatro dos sete municípios que compõem a região litorânea do Paraná: o evento denominado “Águas de Março” deixou mais de R\$ 210 milhões em danos e perdas. Frente a este fato, o Estado criou o projeto Fortalecimento da Gestão de Riscos de Desastres, um marco no processo de reestruturação do Sistema Estadual de Proteção e Defesa Civil, contando com a participação direta do Major Eduardo Gomes Pinheiro.

O Major Eduardo Gomes Pinheiro é pesquisador, pós-doutorando, doutor e mestre em Gestão Urbana pela PUC-PR, sendo também bacharel em Segurança Pública. Especialista em Emergências Ambientais; Administração; Metodologia do Ensino Superior e Educação à Distância e em Redução do Risco de Desastre e Desenvolvimento Local Sustentável, tem se dedicado ao desenvolvimento do Indicador Municipal de Proteção e Defesa Civil (IPDC) - preparação para desastres. No período de 2005 a 2018, como Oficial do Corpo de Bombeiros desenvolveu atividades profissionais na Coordenadoria Estadual de Proteção e Defesa Civil e, atualmente, junto à $1^{\text {a }}$ Coordenadoria Regional de Proteção e Defesa Civil do Paraná. Foi Diretor do Centro Universitário de Estudos e Pesquisas sobre Desastres do Paraná - CEPED/PR e idealizador da Redesastre formalmente instituída por meio de decreto estadual em caráter inovador para integrar Instituições de Ensino Superior e pesquisa em torno da temática da redução do risco de desastres e resiliência. É autor dos livros: Defesa Civil para Prefeitos (2008), Gestão Pública para a Redução dos Desastres: incorporação da variável risco de desastres à gestão das cidades (2015), Orientações para o Planejamento em Proteção e Defesa Civil (2017) e Construindo um Estado Resiliente: o modelo paranaense de gestão de riscos e desastres (2016).

\section{Em que momento e de que forma a Gestão de Risco de Desastre entrou na agenda do Governo do Estado?}

A Defesa Civil surgiu, no Paraná, em 29 de dezembro de 1972. Desde então, houve períodos diferentes que determinaram o grau de protagonismo que a coordenadoria estadual desempenhou ao longo do processo de gestão do risco de desastres. No passado mais recente, foi em 2011 que houve uma combinação de fatores: um grande desastre (Águas de Março), o início de um novo ciclo de governo e as tratativas de um processo 
que culminaria em uma operação de crédito entre o Estado do Paraná com o Banco Mundial. Esse alinhamento proporcionou que, no âmbito do Projeto Multissetorial para o Desenvolvimento do Paraná, surgissem condições para que o Fortalecimento da Gestão de Riscos de Desastres (FGRD) pudesse reunir algumas das instituições diretamente relacionadas com a temática.

\section{Qual o papel do senhor na Operação "Águas de Março", realizada em 2011?}

$\mathrm{Na}$ época, a Coordenadoria Estadual de Proteção e Defesa Civil tinha apenas três Oficiais e um grupo também pequeno de auxiliares. Eu era o Subchefe da Divisão de Defesa Civil da Casa Militar e acabei absorvendo as ações de assessoramento direto ao Coordenador Estadual de Proteção e Defesa Civil na realização das ações de resposta e recuperação dos quatro municípios envolvidos. Isso me permitiu interagir durante a crise com toda a estrutura de governo, possibilitando aquisição de experiência a partir da vivência do evento. Cada desastre tem a propriedade de ensinar algo para os profissionais envolvidos e, também, para as instituições. Aprendi muito com esse evento.

\section{Como o Estado se articulou pós-desastre? Quais foram os principais avanços na área de preparação para desastres?}

O pós-desastre ocorre motivado pela comoção e é influenciado por um conjunto de demandas resultantes do desastre. Eventos de grande porte costumam significar a abertura temporária de janelas de oportunidade para que questões estruturantes possam ser priorizadas, levando ao desenvolvimento de novas soluções. Normalmente, grande parte das mudanças necessárias acaba sendo bem recebida nesse processo pelos diversos setores do governo, gerando o desenvolvimento para a redução do risco de desastre.

\section{A sua trajetória acadêmica também foi influenciada por este evento?}

Quando ocorreu o Águas de Março, eu havia acabado de defender a dissertação de mestrado, versando sobre as relações entre o planejamento urbano e o planejamento em proteção e defesa civil para a redução dos desastres. $\mathrm{O}$ evento ampliou as convicções de que a política urbana brasileira havia deixado lacunas que permitiam que houvesse o surgimento de áreas de risco. Posteriormente, no ano de 2012, com o advento da Política Nacional de Proteção e Defesa Civil, houve um conjunto de alterações específicas no Estatuto da Cidade, aumentando o lastro legal para a adoção de medidas para a redução dos desastres nas cidades. Dessa forma, ao emendar o início do doutorado e mesmo o pós-doutorado que estou finalizando, a temática passou a ser sempre a linha condutora do processo de busca pelo conhecimento para transformar - para melhor - a segurança global das cidades.

\section{Como está o cenário da pesquisa acadêmica voltado à Gestão de Risco de Desastre no Brasil e no Paraná?}

No Brasil, houve uma tentativa de organização voluntária pelos próprios pesquisadores que, em comum, possuem a temática do risco como motivação, para que surgisse a rede de pesquisadores em redução do risco 
de desastre. Entre altos e baixos, o ímpeto de muitos pesquisadores manteve acesa essa chama, apesar da não formalização do grupo. Mesmo assim, por exemplo, o Paraná, por meio do Centro Universitário de Estudos e Pesquisas sobre Desastres - CEPED/PR em conjunto com outras instituições de ensino e com a própria estrutura da defesa civil estadual, organizou a primeira edição do Congresso Brasileiro de Redução do Risco de Desastre, em outubro de 2016. Desde então, surgiram duas associações (uma voltada a profissionais e outra a pesquisadores da área) e outras duas edições do evento: uma no Rio de Janeiro e a que se realizará neste ano, em Belém. Apesar desses avanços, ainda não temos uma sistematização do conhecimento existente resultante de projetos de pesquisa, teses, dissertações e artigos produzidos pela academia. A Redução de Riscos de Desastres (RRD) não é uma área em si, mas um ponto de encontro entre os vários campos do conhecimento caracterizado pela multidisciplinariedade, como são os riscos e, consequentemente, os desastres.

No Estado do Paraná, surgiu em 2013 o CEPED/PR, em um modelo inédito que envolvia a direção geral, instituída pela Coordenadoria de Proteção e Defesa Civil, e a direção acadêmica, representada pela Universidade Estadual do Paraná. Na sequência, para garantir a mobilização das instituições públicas e privadas, institutos e afins, foi criada a Redesastre - primeira (e única) rede temática existente no Brasil para atuar com a produção e difusão de conhecimento útil para a redução do risco de desastre. A Redesastre atua por meio do ensino, pesquisa, extensão e inovação tecnológica. O CEPED/PR captou recursos, firmou parcerias, desenvolveu cursos e financiou projetos em todo o estado, a partir de demandas apontadas pela própria coordenadoria estadual de proteção e defesa civil. A partir de 2019, o Centro está desenvolvendo suas atividades junto à área de ciência e tecnologia, em uma nova configuração.

Evidentemente, é preciso que os gestores percebam o óbvio não apenas nessa área, mas o raciocínio é válido para todos os setores da administração pública: ter a academia por perto e trabalhar em parceria resulta em um processo otimizado, que promove mais assertividade e profissionalismo para as decisões que definem o nosso futuro como sociedade.

\section{Como o senhor vê a integração das práticas e contribuições socioambientais da Academia para a toma- da de decisão da governança pública, seja ela estadual ou municipal? \\ O modelo do CEPED/PR provou que isso é possível, no entanto, é preciso que os gestores entendam o papel e as contribuições que a academia, desde que bem orientada e de forma integrada, pode proporcionar. A aproximação da academia não retira a liberdade do gestor, mas lhe ajuda a errar menos cercando-se de mais conhecimento para tomar as melhores decisões.}

\section{Falando sobre tomada de decisão, qual a importância de mecanismos como o Indicador de Preparação para Desastres nas Cidades (IPCD) no processo de gestão de risco de desastres?}

Indicadores não apenas são instrumentos para monitoramento de políticas públicas como determinam critérios que podem balizar a tomada de decisão. Ao não sabermos, dentre as cinco ações de proteção e defesa civil, como está, pelo menos, o nível de preparação das cidades para o enfrentamento de desastres, não 
poderíamos, sequer, estabelecer critérios tecnicamente adequados para a distribuição de recursos financeiros e treinamento de pessoal, pois não sabemos quais são as prioridades a partir de instrumentos desenvolvidos cientificamente. Esse é um dos papéis da ciência, apoiar a gestão e fazer a diferença na construção de um mundo mais justo e sustentável. O IPDC é um componente na busca por essa realidade, por isso, acredito muito no seu potencial e nos resultados que já coletamos com a sua aplicação em algumas cidades, principalmente de forma associada aos conceitos da campanha Construindo Cidades Resilientes, instituída pela ONU. 